\title{
Maternal Complications and Procedures in Pregnancy and at Birth and Wheezing Phenotypes in Children
}

\author{
Franca Rusconi, Claudia Galassi, Francesco Forastiere, Marta Bellasio, Manuela De Sario, Giovannino Ciccone, \\ Luigia Brunetti, Elisabetta Chellini, Giuseppe Corbo, Stefania La Grutta, Enrico Lombardi, Silvano Piffer, \\ Fiorella Talassi, Annibale Biggeri, Neil Pearce, and the SIDRIA-2 Collaborative Group* \\ Unit of Epidemiology and Pediatric Pulmunology Service, Anna Meyer Children's Hospital; Center of Study and Prevention of Cancer; and \\ Department of Statistics, University of Florence, Florence; Unit of Cancer Epidemiology, San Giovanni Battista Hospital-Center of Cancer \\ Prevention; and Unit of Cancer Epidemiology, Department of Biomedical Sciences and Human Oncology, University of Turin, Turin; Department \\ of Epidemiology, Rome E Local Health Authority; and Department of Respiratory Physiology, Catholic University of Rome, Rome; Department \\ of Pediatrics I, University of Milan, Milan; Department of Pediatrics I, University of Bari, Bari; Pediatric Pulmunology and Allergology Service-ARNAS \\ (Azienda di Rilievo Nazionale ad Alta Specializzazione), IBIM (Istituto di Biomedicina e Immunologia Molecolare) National Research Council, \\ Palermo; Unit of Epidemiology, Provincial Health Authority, Trento; and Unit of Preventive Medicine, Local Health Authority, Mantova, Italy; \\ and Center for Public Health Research, Massey University Wellington Campus, Wellington, New Zealand
}

\begin{abstract}
Rationale: There is increasing interest in the potential influence of fetal and early life conditions on childhood wheezing.

Objectives: To investigate the associations between maternal complications and procedures in pregnancy and at birth and the risk of various wheezing phenotypes in young children.

Methods: We studied 15,609 children, aged 6-7 yr, enrolled in a population-based study. Standardized questionnaires were completed by the children's mothers.

Results: Of the children, $9.5 \%(1,478)$ had transient early wheezing, $5.4 \%(884)$ had persistent wheezing, and $6.1 \%(948)$ had late-onset wheezing. Maternal hypertension or preeclampsia was associated with an increased risk of all three wheezing phenotypes (for transient early wheezing: odds ratio [OR], 1.40; 95\% confidence interval [95\% Cl], 1.08-1.82; for persistent wheezing: OR, 1.59; $95 \% \mathrm{Cl}$, 1.15-2.19; and for late-onset wheezing: $\mathrm{OR}, 1.47$; $95 \% \mathrm{Cl}, 1.06-$ 2.01). Use of antibiotics for urinary tract infections was associated with transient early wheezing (OR, 1.52; 95\% Cl, 1.16-2.00), whereas antibiotic administration at delivery was associated with both transient early wheezing (OR, 1.21; 95\% Cl, 1.01-1.46) and persistent wheezing (OR, 1.39; 95\% Cl, 1.10-1.75). Children who had a mother with diabetes were also more likely to have persistent wheezing (OR, 1.72; 95\% Cl, 0.99-3.00). Neither amniocentesis/ chorionic villus sampling, nor weight gain in pregnancy, nor cesarean section was associated with the subsequent development of wheezing. Maternal asthma or atopy was not an effect modifier of the associations found.

Conclusions: Some maternal complications during pregnancy and at delivery may increase the risk of developing different phenotypes of wheezing in childhood.
\end{abstract}

Keywords: asthma; perinatal; programming

Several studies have considered the possible role of pre- and perinatal factors in the etiology of childhood wheezing and asthma and in the early phenotypic expressions of these diseases

(Received in original form December 29, 2005; accepted in final form September 20, 2006) Supported partially by the Italian Ministry of Health-Regional Health Agency of Emilia-Romagna.

* A complete list of members may be found before the beginning of the reference section.

Correspondence and requests for reprints should be addressed to Franca Rusconi, M.D., Epidemiology Unit, Anna Meyer Children's Hospital, Via Luca Giordano 7/m, 50132 Florence, Italy. E-mail: f.rusconi@meyer.it

This article has an online supplement, which is accessible from this issue's table of contents at www.atsjournals.org

Am J Respir Crit Care Med Vol 175. pp 16-21, 2007

Originally Published in Press as DOI: 10.1164/rccm.200512-19780C on September 22, 2006 Internet address: www.atsjournals.org

\section{AT A GLANCE COMMENTARY}

Scientific Knowledge on the Subject

Maternal smoking in pregnancy influences lung development and is associated with wheezing in childhood; other prenatal and perinatal factors (maternal infections, obstetric conditions) have been inconclusively associated with wheezing among offspring.

\section{What This Study Adds to the Field}

An association was found between maternal hypertension, diabetes, and urinary tract infections during pregnancy and exposure to antibiotics at delivery with wheezing disorders, in particular wheezing of early onset.

(1). The most studied in utero environmental influence on lung development is maternal smoking in pregnancy, which has been shown to be associated not only with wheezing in childhood (2-5) but also with a dose-related reduction in lung function in the newborn period. Fetal development seems therefore to represent a critical time of pulmonary vulnerability with respect to smoking exposure. More recently, some studies have also investigated the relationships between exposure to maternal infections in pregnancy (6-8), maternal obstetric conditions (hyperemesis, hypertension, and preeclampsia) (9-11), uterine factors (antepartum hemorrhage, preterm contractions, placental insufficiency, and uterine growth restriction) (9-11), malposition or malpresentation of the fetus (11), mode of delivery (11-18), and the development of asthma among offspring. However, the findings of these studies have been inconsistent.

In a report published in 1999 (19), we found associations between a number of pre-, peri-, and early postnatal factors and different wheezing phenotypes in a large multicenter crosssectional population-based study, the SIDRIA (Italian Studies of Respiratory Disorders in Childhood and the Environment) phase 1 study, an extension of the International Study on Asthma and Allergies in Childhood (ISAAC) phase 1 study (20). The enrolled children were categorized, on the basis of criteria derived from Martinez and coworkers (21), as transient early wheezers (children with wheezing in the first $2 \mathrm{yr}$ of life but not at school age), persistent wheezers (children who continued to wheeze at school age), late-onset wheezers (children who did not wheeze in the first years of life but who wheezed when 6-7 yr 
old), or nonwheezers (all other children). In that study we focused on the importance of early life factors on the subsequent manifestation of wheezing, and we reported the associations of various exposures with the different wheezing phenotypes.

A second phase of the SIDRIA study was conducted in 2002 in 12 centers in northern, central, and southern Italy to evaluate possible time changes in the prevalence of respiratory disorders in childhood (22), to confirm the role of potential risk factors identified in SIDRIA-1 (23) and to investigate new risk factors. In this article we evaluate the associations between maternal medical complications and procedures during pregnancy and at delivery, and the risks of the various wheezing phenotypes in young children.

The preliminary results of these analyses have been previously reported in the form of an abstract (24).

\section{METHODS}

The full details of the SIDRIA study have been reported elsewhere (23, 25 ), and are described in the online supplement. The current analysis is based on the data for 6- to 7-yr-old children whose questionnaires were completed by their biological mothers alone or together with their fathers. Three mutually exclusive outcomes were included in the analysis: (1) those who had at least one lower respiratory tract illness with wheezing (bronchiolitis or asthmatic bronchitis or asthma or wheezing) in the first $2 \mathrm{yr}$ of life, and had no wheezing in the last $12 \mathrm{mo}$ (transient early wheezers); (2) those who had at least one lower respiratory tract illness with wheezing in the first $2 \mathrm{yr}$ of life, and had wheezing in the last $12 \mathrm{mo}$ (persistent wheezers); and (3) those with no lower respiratory tract illness with wheezing in the first $2 \mathrm{yr}$ of life but who had wheezing in the last $12 \mathrm{mo}$ (late-onset wheezers). The remainder comprised those with no lower respiratory tract illness with wheezing in the first $2 \mathrm{yr}$ of life, no asthma up to 6 to $7 \mathrm{yr}$, and no wheezing in the last $12 \mathrm{mo}$ (nonwheezers). Children for whom data on respiratory diseases in the first $2 \mathrm{yr}$ of life or on wheezing symptoms in the last 12 mo were lacking were excluded from the analysis.

A number of maternal medical complications or procedures during pregnancy and at birth were examined: amniocentesis or chorionic villus sampling, hypertension requiring therapy, preeclampsia, diabetes before or during pregnancy, use of antibiotics for urinary tract infections and for respiratory infections, gestational weight gain classified as low (less than $9 \mathrm{~kg}$ ) or high (greater than $15 \mathrm{~kg}$ ), use of antibiotics at delivery, and cesarean section.

The following potential confounders were identified a priori: study center, parental history of asthma or atopy, maternal smoking in pregnancy, sex of the child, low birth weight (less than 2,500 g), siblings, maternal age at birth, socioeconomic status (parental schooling, mold or damp in child's bedroom during his first year of life), season of the questionnaire's completion, and the person who completed the questionnaire (i.e., the mother alone or together with father).

Missing values were considered as negative responses when frequencies were computed. The proportion with missing values was lower than $7 \%$ for each question. The associations between maternal variables and each group of wheezing children (taking as reference group those without wheezing) were assessed by polytomous logistic regression analysis (26), which allows to assess simultaneously the effects of various factors on three mutually exclusive outcomes. Odds ratios (ORs) were first adjusted only for the potential confounders reported above. Subsequently, we also included the maternal complications and procedures in the multivariate analysis. All the regression models have been performed on the dataset of children with no missing answers to any of the maternal variables or confounders (the complete dataset).

Possible effect modification by maternal history of asthma or allergy was evaluated by introducing interaction terms into the regression models. Birth weight may be an intermediate factor in the causal pathway between maternal complications and wheezing; therefore we also tested the association between maternal variables and wheezing excluding children with a birth weight of less than 2,500 g. Finally, in the evaluation of the role of cesarean section, to control for circumstances that could lead to a decision in favor of instrumental delivery, we also conducted an analysis excluding children who fulfilled any of the following criteria: birth weight less than 2,500 g or greater than 5,000 g, multiple births, or premature delivery (gestational age less than $37 \mathrm{wk}$ ).

To evaluate the robustness of our results to alternative modeling choices, we conducted a sensitivity analysis using a "propensity score" approach (27) as described in the online supplement. The propensity score approach attempts to control for confounding in nonexperimental studies by adjusting for the likelihood that a given subject is exposed. It is used when several explanatory variables are likely to be correlated, as in the case of maternal complications and procedures, and when investigators have no control on the experimental plan of the study as in the case of observational studies, which may increase the risk of selection bias.

Statistical analyses were performed with Stata 8 (StataCorp, College Station, TX).

\section{RESULTS}

Questionnaires were returned for 20,016 children (response rate, $89.2 \%$ ). Questionnaires were completed by the father only, or by a person different from the biological mother, for 1,695 children. Complete data for respiratory diseases in the first $2 \mathrm{yr}$ of life and for wheezing symptoms in the last 12 mo were not available for 2,712 children, leaving a total of 15,609 children (8,003 males and 7,606 females) for the present analysis. The children not included in the analysis differed from those who were included in their lower degree of parental education (university, 19.2\% in those not included and $22.6 \%$ in those included; high school, $42.6 \%$ in those not included and $48.7 \%$ in those included; $p<$ $0.0001)$. The principal characteristics of the children studied are shown in Table 1 . Of these, $9.5 \%(1,478)$ were classified as having had transient early wheezing, 5.4\% (844) as having had persistent wheezing, and $6.1 \%$ (948) as having had late-onset wheezing, whereas $79 \%(12,339)$ were "nonwheezers."

Table 2 shows, for the three wheezing phenotypes and for children without any wheezing history, the frequencies of exposure and the association with maternal medical complications and procedures adjusted for the set of potential confounding factors defined a priori. A borderline statistically significant association was found between amniocentesis or chorionic villus sampling and transient early wheezing. Among maternal health complications during pregnancy, hypertension or preeclampsia was associated with an increased risk of all three wheezing outcomes, whereas prescription of antibiotics for urinary tract infections, and antibiotics administered at delivery, were associated only with early-onset wheezing (including both transient and persistent wheezing). Prescription of antibiotics for respiratory infections was strongly associated with persistent and late-onset wheezing. Maternal diabetes was associated with persistent wheezing. Children born by cesarean section had no increased

\section{TABLE 1. CHARACTERISTICS OF STUDY PARTICIPANTS}

\begin{tabular}{lc}
\hline Characteristic & $\begin{array}{r}\text { Children Studied } \\
(n=15,609)\end{array}$ \\
\hline Age, $\mathrm{yr}($ mean $\pm \mathrm{SD})$ & $6.7 \pm 0.64$ \\
Male sex, $\mathrm{n}(\%)$ & $8,003(51.2)$ \\
Parental history of asthma, $\mathrm{n}(\%)$ & $1,975(12.7)$ \\
Parental history of atopy, $\mathrm{n}(\%)$ & $6,201(39.7)$ \\
Maternal smoking in pregnancy, $\mathrm{n}(\%)$ & $1,809(11.6)$ \\
Low birth weight $(<2,500 \mathrm{~g}), \mathrm{n}(\%)$ & $945(6.1)$ \\
Parental schooling & \\
$\quad$ University, $\mathrm{n}(\%)$ & $3,521(22.6)$ \\
$\quad$ High school $(13 \mathrm{yr}), \mathrm{n}(\%)$ & $7,609(48.7)$ \\
$<13$ yr, $\mathrm{n}(\%)$ & $4,439(28.4)$ \\
Maternal age at birth, mean \pm SD & $30.9 \pm 4.9$ \\
Mold or damp in child's bedroom during the first year of & $1,969(12.6)$ \\
$\quad$ life, $\mathrm{n}(\%)$ & \\
\hline
\end{tabular}


TABLE 2. ASSOCIATIONS OF MATERNAL COMPLICATIONS OR PROCEDURES DURINC PREGNANCY AND AT BIRTH WITH VARIOUS TYPES OF WHEEZING IN YOUNG CHILDREN

\begin{tabular}{|c|c|c|c|c|}
\hline Maternal Complications or Procedures & $\begin{array}{l}\text { Nonwheezers } \\
(n=12,339)\end{array}$ & $\begin{array}{c}\text { Transient Early } \\
\text { Wheezing } \\
(n=1,478)\end{array}$ & $\begin{array}{l}\text { Persistent } \\
\text { Wheezing } \\
(n=844)\end{array}$ & $\begin{array}{l}\text { Late-Onset } \\
\text { Wheezing } \\
(n=948)\end{array}$ \\
\hline \multicolumn{5}{|l|}{ Amniocentesis or chorionic villus sampling } \\
\hline Frequency, \% & 18.5 & 19.6 & 17.8 & 18.6 \\
\hline OR $(95 \% \mathrm{Cl})$ & & $1.19(1.00-1.42)$ & $0.98(0.77-1.24)$ & $1.08(0.87-1.34)$ \\
\hline \multicolumn{5}{|l|}{ Hypertension or preeclampsia } \\
\hline Frequency, \% & 5.2 & 7.4 & 7.6 & 6.9 \\
\hline OR $(95 \% \mathrm{Cl})$ & & $1.47(1.14-1.89)$ & $1.71(1.25-2.36)$ & $1.45(1.06-1.48)$ \\
\hline \multicolumn{5}{|l|}{ Diabetes } \\
\hline Frequency, \% & 1.5 & 2 & 2 & 1.8 \\
\hline OR $(95 \% \mathrm{Cl})$ & & $1.39(0.87-2.23)$ & $1.84(1.06-3.20)$ & $0.97(0.49-1.91)$ \\
\hline \multicolumn{5}{|c|}{ Antibiotics for urinary tract infections in pregnancy } \\
\hline Frequency, \% & 3.8 & 5.8 & 5.7 & 5 \\
\hline OR $(95 \% \mathrm{Cl})$ & & $1.57(1.20-2.06)$ & $1.31(0.89-1.91)$ & $1.13(0.77-1.65)$ \\
\hline \multicolumn{5}{|c|}{ Antibiotics for respiratory infections in pregnancy } \\
\hline Frequency, \% & 1.8 & 2.8 & 4.3 & 3.0 \\
\hline OR $(95 \% \mathrm{Cl})$ & & $0.99(0.54-1.83)$ & $2.91(1.73-4.86)$ & $2.25(1.32-3.83)$ \\
\hline \multicolumn{5}{|l|}{ Weight gain $<9 \mathrm{~kg}$} \\
\hline Frequency, \% & 13.8 & 13.6 & 14 & 14.1 \\
\hline OR $(95 \% \mathrm{Cl})$ & & $1.00(0.83-1.22)$ & $1.09(0.85-1.40)$ & $1.12(0.89-1.40)$ \\
\hline \multicolumn{5}{|l|}{ Weight gain $>15 \mathrm{~kg}$} \\
\hline Frequency, \% & 18.1 & 21 & 21.8 & 17.8 \\
\hline OR $(95 \% \mathrm{Cl})$ & & $1.14(0.97-1.34)$ & $1.23(0.85-1.40)$ & $0.94(0.76-1.40)$ \\
\hline \multicolumn{5}{|l|}{ Antibiotics at delivery } \\
\hline Frequency, \% & 12.9 & 16.1 & 18.6 & 14.6 \\
\hline OR $(95 \% \mathrm{Cl})$ & & $1.25(1.05-1.48)$ & $1.44(1.17-1.79)$ & $1.04(0.83-1.29)$ \\
\hline \multicolumn{5}{|l|}{ Cesarean section } \\
\hline Frequency, \% & 26.5 & 27.3 & 29.3 & 25.6 \\
\hline OR $(95 \% \mathrm{Cl})$ & & $1.04(0.90-1.20)$ & $1.12(0.93-1.36)$ & $0.99(0.83-1.19)$ \\
\hline
\end{tabular}

Definition of abbreviations: $\mathrm{Cl}$ = confidence interval; $\mathrm{OR}=$ odds ratio.

The ORs were estimated with polytomous logistic regression including as confounders: study center, parental history of asthma or atopy, maternal smoking in pregnancy, maternal age at birth, sex, low birth weight, siblings, socioeconomic status (parental schooling, mold or damp in child's bedroom during his first year of life), season of the questionnaire's completion, and person who completed the questionnaire. The logistic regression analyses have been performed on the complete dataset (no missing answers to any of the variables), including the following: nonwheezers $=9,740$; transient early wheezing $=1,124$; persistent wheezing $=611$; late-onset wheezing $=712$.

risk of wheezing, not even when children with conditions possibly related to instrumental delivery $(6.2 \%$ of the whole sample) were excluded from the analysis.

The associations between various maternal complications and procedures and the wheezing outcomes, mutually adjusted by logistic regression analysis, are shown in Table 3 . In this analysis we decided not to include in the multivariate model the administration of antibiotics for respiratory infections in pregnancy, which, in the previous model, was strongly associated with an increased risk of persistent and late-onset wheezing. In fact, mothers with a diagnosis of asthma were more likely to be treated during pregnancy with antibiotics for respiratory infections

TABLE 3. ASSOCIATIONS OF MATERNAL COMPLICATIONS OR PROCEDURES DURING PREGNANCY AND AT BIRTH WITH WHEEZING IN YOUNG CHILDREN IN REGRESSION ANALYSIS WITH MUTUAL ADJUSTMENT

\begin{tabular}{|c|c|c|c|}
\hline Maternal Complications or Procedures & $\begin{array}{c}\text { Transient Early } \\
\text { Wheezing }\end{array}$ & $\begin{array}{l}\text { Persistent } \\
\text { Wheezing }\end{array}$ & $\begin{array}{l}\text { Late-Onset } \\
\text { Wheezing }\end{array}$ \\
\hline Amniocentesis or chorionic villus sampling & $1.19(1.00-1.43)$ & $0.97(0.76-1.23)$ & $1.07(0.87-1.34)$ \\
\hline Hypertension or preeclampsia & $1.40(1.08-1.82)$ & $1.59(1.15-2.19)$ & $1.47(1.06-2.01)$ \\
\hline Diabetes & $1.33(0.83-2.14)$ & $1.72(0.99-3.00)$ & $0.94(0.47-1.86)$ \\
\hline Antibiotics for urinary tract infections in pregnancy & $1.52(1.16-2.00)$ & $1.21(0.83-1.79)$ & $1.12(0.76-1.64)$ \\
\hline \multicolumn{4}{|l|}{ Weight gain: } \\
\hline$<9 \mathrm{~kg}$ & $1.00(0.82-1.21)$ & $1.08(0.84-1.39)$ & $1.11(0.89-1.40)$ \\
\hline$>15 \mathrm{~kg}$ & $1.12(0.96-1.31)$ & $1.20(0.98-1.48)$ & $0.93(0.75-1.14)$ \\
\hline Antibiotics at delivery & $1.21(1.01-1.46)$ & $1.39(1.10-1.75)$ & $1.03(0.81-1.30)$ \\
\hline Cesarean section & $0.95(0.81-1.11)$ & $0.97(0.78-1.19)$ & $0.96(0.79-1.17)$ \\
\hline
\end{tabular}

Reference group: nonwheezers. Values represent odds ratios, with 95\% confidence intervals shown in parentheses. The odds ratios were estimated with polytomous logistic regression, including the variables shown in addition to all the following variables: study center, parental history of asthma or atopy, maternal smoking in pregnancy, maternal age at birth, sex, low birth weight, siblings, socioeconomic status (parental schooling, mold or damp in child's bedroom during his first year of life), season of the questionnaire's completion, person who completed the questionnaire. The logistic regression analysis has been performed on the complete dataset (no missing answers to any of the variables), including the following: nonwheezers $=9,740$; transient early wheezing $=1,124$; persistent wheezing $=611$; late-onset wheezing $=712$. 
( $4.7 \%$, in comparison with $1.9 \%$ of mothers without a diagnosis of asthma), and we were concerned that this could affect the association with wheezing in the offspring. As in the previous analysis (Table 2), maternal hypertension or preeclampsia was associated with all the wheezing phenotypes, antibiotics administered during pregnancy for urinary tract infections were associated only with transient early wheezing, and antibiotics administered at delivery were associated with both transient and persistent wheezing (Table 3 ). There was a borderline statistically significant association (OR, 1.72; 95\% CI, 0.99-3.00) between maternal diabetes before and/or during pregnancy and persistent wheezing; the wide confidence interval observed is due to the low number of women affected by this condition. Children of low birth weight were not more likely to wheeze than children with a birth weight of at least $2,500 \mathrm{~g}$ and the OR $(95 \% \mathrm{CI})$ values were 1.05 (0.81-1.38), $0.96(0.67-1.39)$, and $0.71(0.49-1.05)$ for transient early wheezing, persistent wheezing, and late-onset wheezing, respectively. As a consequence, the strength and the direction of associations between the various maternal variables and different wheezing phenotypes did not change when we excluded from the analysis children of low birth weight.

A maternal history of asthma and/or atopy did not modify the association between maternal complications or procedures in pregnancy and at birth and wheezing phenotypes. No association with cesarean section was found after the exclusion of conditions possibly related to instrumental delivery. Finally, the propensity score analysis (results presented in the online supplement) yielded results similar to those obtained by multiple logistic regression, which are reported in Table 3.

\section{DISCUSSION}

The findings of the present study suggest that maternal complications during pregnancy and at birth may be associated with the development of wheezing disorders in young children. If these findings are causal, they are generally consistent with the concept of "programming," which occurs when an event in a critical early period of an organism's life permanently changes its structure or function. This hypothesis has received extensive interest on the basis of accumulating evidence of a relationship between early life environmental factors and a wide range of chronic diseases, particularly hypertension and diabetes (28, 29), but also, although less conclusively, obstructive lung disease (30-32). The greater influence of maternal compared with paternal asthma and atopy on the development of asthma in offspring suggests that the pre- and perinatal environment also plays a role in the subsequent development of respiratory disease in children $(19,33)$.

In the present study we identified three maternal health complications during pregnancy as risk factors for wheezing in childhood: hypertension requiring therapy during pregnancy or preeclampsia, diabetes, and urinary tract infections treated with antibiotics. Whereas the first factor was associated with all three wheezing phenotypes, the other two were risk factors only for persistent wheezing and transient early wheezing, respectively. The relationship between maternal hypertension in pregnancy and asthma development in the offspring has, to our knowledge, previously been investigated in only one study (11). This was a retrospective study of a cohort of 4,065 children and adolescents aged 1 to $18 \mathrm{yr}$, and it did not find an association with an increased lifetime asthma risk. Our findings suggest that abnormalities in the fetal placental circulation occurring in hypertensive pregnancies, as well as in diabetic pregnancies $(34,35)$, may result in fetal airway damage. Another possible explanation is that hypertension in pregnancy may result in fetal growth restriction and hence in diminished airway function (36). In diabetic pregnan- cies, a delay in the production of phosphatidylglycerol and hence a surfactant deficiency, together with an increased susceptibility to respiratory distress syndrome, could also account for the excess risk of persistent wheezing in infants (37).

The role of maternal infections in pregnancy in the development of asthma has been explored in three cohort studies in Denmark (8), Finland (6), and the United Kingdom (7). In the first study (8), antibiotic use in pregnancy was not associated with hospital admission for asthma or wheezing bronchitis in the first $3 \mathrm{yr}$ of life in the offspring, whereas an association was found with antiasthma medication during the fifth year of life. In the study conducted by $\mathrm{Xu}$ and coworkers (6), children had a higher risk of asthma by age $7 \mathrm{yr}$ if their mothers experienced vaginitis and febrile infections during pregnancy. McKeever and coworkers (7) suggested that exposure to antibiotics or infection in utero is associated with an increased dose-related risk of asthma and wheezing, as well of eczema and hay fever; children who had experienced these exposures had an early age of onset of asthma or wheeze (mean, $1.6 \mathrm{yr}$ ). In that study, a high percentage of mothers, approximately one-third, were prescribed one or more courses of antibiotics during pregnancy, most commonly for respiratory tract infections. We were concerned that respiratory infections treated with antibiotics may indicate a predisposition for asthma in the mother, and also that in a retrospective study mothers may preferentially recall respiratory problems if their children developed wheezing. Thus in the final analysis we chose to focus on urinary tract infections treated with antibiotics. Urinary tract infections in pregnancy are believed to be a marker of abnormal colonization of the genitourinary tract and to predispose women to chorioamnionitis $(38,39)$. A possible explanation for our findings may be that antenatal infections or inflammation associated with chorioamnionitis could modulate lung development and injury (40). Alternatively, as discussed by other investigators, antibiotics can cross the placenta and enter the fetal circulation or can modify maternal microbial load during pregnancy (7), and have an effect on infant gut colonization and hence on the maturation and differentiation of the mucosal immune system $(41,42)$. This may also explain the small increase in risk of early-onset wheezing we found in children of mothers who received antibiotics at delivery.

We found no evidence that cesarean section, which also has been reported to have an impact on gut colonization (43), is associated with an increasing risk of developing wheezing. Previous studies (11-18) of this issue have produced inconsistent results. There are a number of methodologic issues that should be evaluated when considering the association between asthma and cesarean birth: criteria for selection of the study population (i.e., exclusion or inclusion of premature or low birth weight infants), controlling for factors associated with cesarean delivery (i.e., prematurity, maternal obesity, maternal asthma, and social class), variations in the ratio of emergency and elective cesarean section in different regions, as well as duration of follow-up. The issue warrants further research, particularly in light of the continually increasing rate of cesarean section in many countries (44).

Maternal asthma or atopy was not an effect modifier of the associations found, that is, the degree of association between maternal complications or procedures in pregnancy and wheezing was similar among children whose mothers had a positive history of asthma or atopy and children of mothers with a negative history. This does not mean that maternal asthma or atopy does not increase the risk of asthma in the child; rather it means that the effect of maternal asthma or atopy does not modify the effects of maternal complications and procedures in pregnancy. 
Our study was population based and included a large group of subjects to ensure adequate statistical power. To assess the independent role of early life factors in the development of wheezing, we adjusted for a large number of factors that could predispose to childhood asthma. However, we were not able to control for additional confounders (e.g., prenatal exposure to air pollution other than passive smoking [45] or paracetamol use in pregnancy [46]), or to take into account other possible maternal complications in pregnancy (e.g., premature rupture of the membranes) and the impact of intrauterine growth retardation.

In performing the multivariate analysis, we realized that some of the variables were somehow correlated, for example, cesarean section and antibiotics at delivery, preeclampsia and low birth weight, and amniocentesis or chorionic villous sampling and maternal age, with the possibility of underestimating the risk because of overadjustment. The propensity score approach, however, yielded similar results when compared with the more traditional approach we adopted.

The retrospective design of the study raises a number of issues, including the validity of a questionnaire that asks mothers to recall events that occurred 7 to $8 \mathrm{yr}$ in the past. The validity of some items was evaluated in a pilot study in one center (Trento Province) in which administrative data collected at birth were available (results are reported in the online supplement). Other studies have suggested reasonable reliability and validity for long-term maternal recall of events and medical complications during pregnancy, labor, or delivery $(47,48)$. Mothers may recall more accurately events that they believe are especially relevant, such as amniocentesis or cesarean section, or that they have previously noted at gynecologic visits during pregnancy or at admission to hospital, such as hypertension or diabetes or infections during pregnancy. However, such selective recall would produce significant bias only if over (or under) reporting of such exposures was different between mothers of children with wheezing and those of nonwheezers. This seems unlikely for pregnancy complications, particularly because the participants were not given any information about their possible associations with wheezing in their offspring.

The retrospective design of the study could have resulted in a reduced recall of milder wheezing symptoms. To increase specificity, particularly for wheezing in the first $2 \mathrm{yr}$ of life, we asked parents to report episodes of bronchiolitis or asthmatic bronchitis in addition to wheezing. Our estimated prevalence of wheeze in the first $6 \mathrm{yr}$ of life is lower than that reported in the prospective Tucson Children's Respiratory Cohort Study by Martinez and coworkers (21), and in a retrospective survey in Leicester in the United Kingdom (49). This is in line with the ISAAC phase 1 findings, which showed that wheezing prevalence in school-age children and adolescents in Italy is considerably lower than that in the United States, New Zealand, and the United Kingdom, and also lower than that in most other nonEnglish-speaking European countries (20). Regarding misclassification of children with different wheezing phenotypes and of nonwheezers, we may have included in the nonwheezer group or in the late-onset wheezer group a number of children who had milder symptoms in the first $2 \mathrm{yr}$ of life, or we may have missed mild symptoms occurring in the 12 mo preceding the questionnaire completion. However, such misclassification is likely to have been nondifferential (i.e., unrelated to exposure) and would therefore have biased the ORs toward the null value (50).

In conclusion, intrauterine factors other than maternal smoking in pregnancy have been suggested to play a role in different populations and settings in the development of wheezing and asthma. Our findings suggest that maternal hypertension, diabe- tes, and urinary tract infections during pregnancy and exposure to antibiotics at delivery are potential risk factors for the development of different wheezing disorders, in particular for wheezing of early onset, a pattern of wheezing associated with congenital impairment of airway function $(51,52)$.

Our work was intended mainly to generate hypotheses regarding potential mechanisms occurring in pregnancy and around the time of birth, such as effects on the structural development of the fetal lung and on the maturation of the infant immune system. This gives suggestions for future prospective investigations to confirm the findings and to explore possible biological mechanisms and the different contribution of risk factors to different wheezing conditions, particularly early-onset wheezing.

Conflict of Interest Statement: None of the authors has a financial relationship with a commercial entity that has an interest in the subject of this manuscript.

SIDRIA-2 Collaborative Group: G. Ciccone, D. Mirabelli, and E. Migliore (CPO, Turin); G. Berti, and E. Cadum (ARPA, Turin); M. Bugiani and P. Piccioni (CPA, ASL 4, Turin); L. Bisanti and A. Russo (ASL, Milan); F. Rusconi (University of Milan and AOU Meyer, Florence); M. Bellasio (University of Milan); V. Gianelle (ARPA, Milan); S. Piffer, L. Battisti, D. Kaisermann, and M. Gentilini (APSS, Trento); G. Giannella and F. Talassi (ASL, Mantua); C. Galassi (ASR, Emilia Romagna and CPO, Turin); N. Caranci, G. Frasca, and M. Biocca (ASR, Emilia Romagna); E. De Munari (ARPA, Emilia Romagna); E. Chellini (CSPO, Florence); E. Lombardi (AOU Meyer, Florence); A. Biggeri and C. Gabellini (University of Florence), D. Grechi (ARPAT, Florence); M. G. Petronio (ASL, Empoli); P. Sestini (University of Siena); G. Viegi and M. Simoni (CNR, Pisa); F. Forastiere, M. De Sario, and N. Agabiti (ASL RM/ E, Rome); R. Pistelli and G. Corbo (Università S. Cuore, Rome); E. Bonci and L. Indinnimeo (ISS, Rome); V. Dell'Orco (ASL RM/G, Rome); L. Armenio, L. Brunetti, M. Cavone, M. L. Lospalluti, M. Massagli, G. Polieri, D. Rizzi, F. R. Rana and M. Rana (University of Bari); and S. La Grutta (ARNAS and IBIM-CNR, Palermo, Italy).

Acknowledgment: The SIDRIA-2 Collaborative Group is grateful to all schoolchildren and their parents for participation, and to the teachers and school directors for helpful collaboration. The authors especially thank all the physicians and staff members of the National Health Service for their important work in the collection of data. Neil Pearce's work on this article was supported by the Health Research Council of New Zealand and the Progetto Lagrange, Fondazione CRT/ISI.

\section{References}

1. Bracken MB, Belanger K, Cookson WO, Triche E, Christiani DC, Leaderer BP. Genetic and perinatal risk factors for asthma onset and severity: a review and theoretical analysis. Epidemiol Rev 2002;24: 176-189.

2. Agabiti N, Mallone S, Forastiere F, Corbo GM, Ferro S, Renzoni E, Sestini P, Rusconi F, Ciccone G, Viegi G, et al.; SIDRIA Collaborative Group. The impact of parental smoking on asthma and wheezing. Epidemiology 1999;10:692-698.

3. Hanrahan JP, Tager IB, Segal MR, Tosteson TD, Castile RG, Vunakis HV, Weiss ST, Speizer FE. The effect of maternal smoking during pregnancy on early infant lung function. Am Rev Respir Dis 1992; 145:1129-1135

4. Stick SM, Burton PR, Gurrin L, Sly PD, Le Souef PN. Effects of maternal smoking during pregnancy and a family history of asthma on respiratory function in newborn infants. Lancet 1996;348:1060-1064.

5. Gilliland FD, Li YF, Peters JM. Effects of maternal smoking during pregnancy and environmental tobacco smoke on asthma and wheezing in children. Am J Respir Crit Care Med 2001;163:429-436.

6. Xu B, Pekkanen J, Jarvelin M-R, Olsen P, Hartikainen A-L. Maternal infections in pregnancy and the development of asthma among offspring. Int J Epidemiol 1999;28:723-727.

7. McKeever TM, Lewis SA, Smith C, Hubbard R. The importance of prenatal exposures on the development of allergic disease: a birth cohort study using the West Midlands general practice database. Am J Respir Crit Care Med 2002;166:827-832.

8. Benn CS, Thorsen P, Jensen JS, Kiaer BB, Bisgaard H, Andersen M, Rostgaard K, Bjorksten B, Melbye M. Maternal vaginal microflora during pregnancy and the risk of asthma hospitalization and use of antiasthma medication in early childhood. J Allergy Clin Immunol 2002;110:72-77.

9. Nafstad P, Magnus P, Jaakkola JJK. Risk of childhood asthma and allergic rhinitis in relation to pregnancy complications. J Allergy Clin Immunol 2000;106:867-873. 
10. Nafstad P, Samuelson SO, Irgens LM, Bjekerdal T. Pregnancy complications and the risk of asthma among Norwegians born between 1967 and 1993. Eur J Epidemiol 2003;18:755-761.

11. Annesi-Maesano I, Moreau D, Strachan D. In utero and perinatal complications preceding asthma. Allergy 2001;56:491-497.

12. McKeever TM, Lewis SA, Smith C, Hubbard R. Mode of delivery and risk of developing allergic disease. J Allergy Clin Immunol 2002;109: 800-802.

13. Xu B, Pekkanen J, Hartikainen A-L, Jarvelin M-R. Caesarean section and risk of asthma and allergy in adulthood. J Allergy Clin Immunol 2001;107:732-733.

14. Kero J, Gissler M, Gronlund M, Kero P, Koskinen P, Hemminki E, Isolauri E. Mode of delivery and asthma: is there a connection? Pediatr Res 2002;52:6-11.

15. Negele K, Heinrich J, Borte M, von Berg A, Schaaf B, Lehmann I, Wichmann HE, Bolte G; LISA Study Group. Mode of delivery and development of atopic disease during the first 2 years of life. Pediatr Allergy Immunol 2004;15:48-54.

16. Maitra A, Sheriff A, Strachan D, Henderson J; ALSPAC Study Team. Mode of delivery is not associated with asthma or atopy in childhood. Clin Exp Allergy 2004;34:1349-1355.

17. Bager P, Melbye M, Rostgaard K, Benn CS, Westergaard T. Mode of delivery and risk of allergic rhinitis and asthma. J Allergy Clin Immunol 2003;111:51-56

18. Salam MT, Margolis HG, McConnell R, McGregor JA, Avol EL, Gilliland FD. Mode of delivery is associated with asthma and allergy occurrence in children. Ann Epidemiol 2006;16:341-346.

19. Rusconi F, Galassi C, Corbo GM, Forastiere F, Biggeri A, Ciccone G, Renzoni E; SIDRIA Collaborative Group. Risk factors for early, persistent, and late-onset wheezing in young children. Am J Respir Crit Care Med 1999;160:1617-1622.

20. International Study of Asthma and Allergies in Childhood (ISAAC) Steering Committee. Worldwide variation in prevalence of symptoms of asthma, allergic rhino-conjunctivitis, and atopic eczema. Lancet 1998;351:1225-1232.

21. Martinez FD, Wright AL, Taussig LM, Holberg CG, Halonen M, Morgan WJ; Group Health Medical Associates. Asthma and wheezing in the first six years of life. N Engl J Med 1995;332:133-138.

22. Galassi C, De Sario M, Biggeri A, Bisanti L, Chellini E, Ciccone G, Petronio MG, Piffer S, Sestini P, Rusconi F, et al. Changes in prevalence of asthma and allergies among children and adolescents in Italy, 1994-2002. Pediatrics 2006;117:34-42.

23. Simoni M, Lombardi E, Berti G, Rusconi F, La Grutta S, Piffer S, Petronio MG, Galassi C, Forastiere F, Viegi G; SIDRIA-2 Collaborative Group. Mould/dampness exposure at home is associated with respiratory disorders in Italian children and adolescents: the SIDRIA-2 Study. Occup Environ Med 2005;62:616-622.

24. Rusconi F, Galassi C, Bellasio M, Forastiere F, Corbo GM, Piffer S; SIDRIA-2 Collaborative Group. Pregnancy complications and risk of wheezing and allergic symptoms in young children [abstract]. Am J Respir Crit Care Med 2004;169:A144.

25. Galassi C, Forastiere F, Biggeri A, Gabellini C, De Sario M, Ciccone G, Biocca M, Bisanti L; SIDRIA-2 Collaborative Group. SIDRIA second phase: objectives, study design and methods. Epidemiol Prev 2005;29: $9-13$.

26. Agresti A. Analysis of categorical data. New York: John Wiley \& Sons; 1990.

27. Rosenbaum PR, Rubin DB. The central role of the propensity score in observational studies for causal effects. Biometrika 1983;70:41-54.

28. Gluckman PD, Hanson MA. Living with the past: evolution, development, and pattern of disease. Science 2004;305:1733-1736.

29. Barker DJP. The developmental origins of adult disease. Eur J Epidemiol 2003; 18:733-736.

30. Barker DJ, Godfrey KL, Fall C, Osmond C, Winter PD, Shaheen SO. Relation of birth weight and childhood respiratory infection to adult lung function and death from chronic obstructive lung disease. BMJ 1991;303:671-675.

31. Shaheen SO, Sterne JA, Tucker JS, du Florey C. Birth weight, childhood lower respiratory tract infection, and adult lung function. Thorax 1998:53:549-553.

32. Edwards CA, Osman LM, Godden DJ, Campbell DM, Douglas JG. Relationship between birth weight and adult lung function: controlling for maternal factors. Thorax 2003;58:1061-1065.

33. Moffat MF, Cookson WO. The genetics of asthma: maternal effects in atopic disease. Clin Exp Allergy 1998;25:58-61.

34. Read MA, Leitch IM, Giles WB, Bisits AM, Boura AL, Walters WA. U46619-mediated vasoconstriction of the fetal placental vasculature in vitro in normal and hypertensive pregnancies. J Hypertens 1999;17: 389-396.

35. Wilkes BM, Mento PF, Hollander AM. Reduced thromboxane receptor affinity and vasoconstrictor responses in placentae from diabetic pregnancies. Placenta 1994;15:845-855.

36. Loom S, Hoo A-F, Dezateux C, Goetz I, Wade A, DeRooy L, Costeloe $\mathrm{K}$, Stocks J. The association between birthweight, sex, and airway function in infants of nonsmoking mothers. Am J Respir Crit Care Med 2001;164:2078-2084.

37. Moore TR. Diabetes in pregnancy. In: Creasy RK, Resnik R, Iams JD, editors. Maternal-fetal medicine: principles and practice, 5 th ed. New York: Elsevier; 2004. pp. 1023-1062.

38. Mittal P, Wing DA. Urinary tract infections in pregnancy. Clin Perinatol 2005;32:749-764.

39. Goldenberg RL, Hauth JC, Andrews WW. Intrauterine infection and preterm delivery. $N$ Engl J Med 2000;342:1500-1507.

40. Jobe AH, Ikegami M. Antenatal infection/inflammation and postnatal lung maturation and injury. Respir Res 2001;2:27-32.

41. Sudo N, Sawamura S, Tanaka K, Aiba Y, Kubo C, Loga Y. The requirement of intestinal bacterial flora for the development of an IgE production system fully susceptible to oral tolerance induction. J Immunol 1997;159:1739-1745.

42. Akbari O, Stock P, DeKruyff RH, Umetsu DT. Role of regulatory T cells in allergy and asthma. Curr Opin Immunol 2003;15:627-633.

43. Gronlund MM, Lehtonen OP, Eerola E, Kero P. Fecal microflora in healthy infants born by different methods of delivery: permanent changes in intestinal flora after cesarean delivery. J Pediatr Gastroenterol Nutr 1999;28:19-25.

44. Caesarean section on the rise [editorial]. Lancet 2000;356:1697.

45. Sram RJ, Binkova B, Dejmek J, Bobak M. Ambient air pollution and pregnancy outcomes: a review of the literature. Environ Health Perspect 2005;113:375-382.

46. Shaheen SO, Newson RB, Sheriff A, Henderson AJ, Heron JE, Burney PGJ, Golding J; ALSPAC Study Team. Paracetamol use in pregnancy and wheezing in early childhood. Thorax 2002;57:958-963.

47. Harlow SD, Linet MS. Agreement between questionnaire data and medical records: the evidence for accuracy of recall. Am J Epidemiol 1989;129:233-248.

48. Tomeo CA, Rich-Edwards JW, Michels KB, Berkey CS, Hunter DJ, Frazier AL, Willett WC, Buka SL. Reproducibility and validity of maternal recall of pregnancy-related events. Epidemiology 1999;10; 774-777.

49. Kuehni CE, Davis A, Brooke MA, Silverman S. Are all wheezing disorders in very young (preschool) children increasing in prevalence? Lancet 2001;357:1821-1825.

50. Copeland KT, Checkoway H, McMichael AJ, Holbrook RH. Bias due to misclassification in the estimation of relative risk. Am J Epidemiol 1977;105:488-495.

51. Tager IB, Hanrahan JP, Tostesan TD, Castile RG, Brown RW, Weiss ST, Speizer FE. Lung function, pre- and post-natal smoking exposure, and wheezing in the first year of life. Am Rev Respir Dis 1993;147:811817.

52. Martinez FD, Morgan WJ, Wright AL, Holberg CJ, Taussig LM. Diminished lung function as a predisposing factor for wheezing respiratory illness in infants. N Engl J Med 1998;319:112-117. 